\title{
INBEX OPUSCULORUM.
}

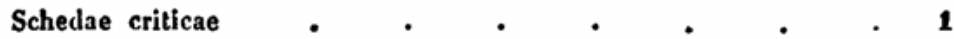

Dissertatio critica, qua Tzetzae ad Hesiodum locus restituitur et

Callimachus aliquoties illustratur, emendatur, suppletur . $\quad 53$

Prooemia et programmata scholis festisque indicendis scripta I-XXXVI 71

Orationes duae natalibus Friderici Guilelmi III celebrandis habitae 276

De Battaro Valerii Catonis . $\quad$ - $\quad$ - $\quad$. 303

Prip̧cipis Serenissimi Friderici Wilhelmi, Borussicl regni heredis, iter

Rhenanum ..$\quad$. $\quad 313$

Herrn Geheimen Staatsrath Niebuhr . $\quad$ • $\quad$. 318

Valerii Catonis poemata recensuit - C. Putschius 1828. (Censura

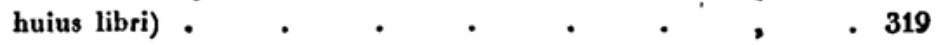

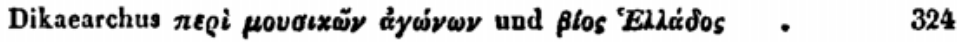

$\begin{array}{llll}\text { Miscella critica } & \text { - } & \mathbf{3 5 0}\end{array}$ 
